\title{
KAJIAN APLIKASI PANTULAN SINYAL GNSS UNTUK PEMANTAUAN KETINGGIAN PERMUKAAN AIR LAUT
}

\author{
Buldan Muslim ${ }^{1, *}$, Charisma Juni Kumalasari ${ }^{2}$, Novie Chiuman ${ }^{3}$, Muhammad Ichsan Fadhil \\ $\operatorname{Arafah}^{3}$ \\ ${ }^{1}$ Pusat Sains Antariksa, LAPAN \\ Jl Dr. Junjunan 133 Bandung 40173 \\ ${ }^{2}$ Program Studi Matematika S2, Institut Teknologi Sepuluh Nopember (ITS) \\ ${ }^{3}$ Departemen Teknik Geodesi, Universitas Gadjah Mada \\ *E-mail korespondensi: mbuldan@gmail.com
}

\begin{abstract}
Designand experiment of ocean current power generation system have been carried out using the Bach In Indonesia, the tsunami early warning system only applies the earthquake and hydrosphere relationship model to predict tsunamis. To date, no tsunami detector has used radar or GNSS technology. GNSS technology can be applied as an early warning system for tsunamis, provided that tsunamis are caused by earthquakes greater than 7 magnitudes, occur 70 kilometers below sea level, and are caused by normal faults. This could be an alternative to Bouy GNSS which is expensive to install and maintain, especially for countries with vast oceans such as Indonesia. In this paper, a review of the application of GNSS signal reflection was carried out using one International GNSS Service (IGS) station, JOG2, and one Continuously Operating Reference Station (CORS), CLSA, each located in Java and Sumatra to investigate the availability of sea level monitoring in Indonesia. Determination of sea level is obtained from two methods, the GNSS signal phase data analysis method and the GNSS Signalto-Noise Ratio (SNR) data analysis method. Both methods use reflected GNSS signals or multipath effects to obtain sea level. The results of the study show that the number of satellites that pass through Indonesia every 15 minutes is enough to get sea-level data every 15 minutes to one hour. This shows that it is possible to apply the multipath effect to obtain sea level information in Indonesia to detect tides and tsunamis as part of the tsunami early warning system in Indonesia.
\end{abstract}

Keywords: GNSS, Signal, Reflection, Sea surface, Tsunami

\begin{abstract}
ABSTRAK
Di Indonesia, sistem peringatan dini tsunami hanya menerapkan model hubungan gempa bumi dan hidrosfer untuk memprediksi tsunami. Hingga saat ini, tidak ada detektor tsunami yang menggunakan teknologi radar atau GNSS. Teknologi GNSS dapat diterapkan sebagai sistem peringatan dini untuk tsunami, dengan ketentuan bahwa tsunami disebabkan oleh gempa bumi lebih besar dari 7 SR, terjadi 70 kilometer di bawah permukaan laut, dan disebabkan oleh patahan normal. Ini bisa menjadi alternatif untuk Bouy GNSS yang mahal untuk menginstal dan memelihara, terutama untuk negara dengan lautan yang sangat luas seperti Indonesia. Dalam makalah ini, kajian aplikasi pantulan sinyal GNSS dilakukan menggunakan satu stasiun International GNSS Service (IGS), JOG2, dan satu Continuously Operating Reference Station (CORS), CLSA, yang masing-masing berlokasi di Jawa dan Sumatra untuk menyelidiki ketersediaan monitoring ketinggian permukaan laut di Indonesia. Penentuan ketinggian permukaan laut diperoleh dari dua metode, metode analisis data fase sinyal GNSS dan metode analisis data Signal-toNoise Ratio (SNR) GNSS. Kedua metode menggunakan sinyal GNSS yang dipantulkan atau efek multipath untuk mendapatkan ketinggian permukaan laut. Hasil dari kajian menunjukkan bahwa jumlah satelit yang melewati Indonesia setiap 15 menit sudah cukup untuk mendapatkan data ketinggian permukaan laut untuk setiap 15 menit hingga satu jam. Ini menunjukkan bahwa adalah mungkin untuk menerapkan efek multipath untuk mendapatkan informasi ketinggian permukaan laut di Indonesia untuk mendeteksi pasang surut dan tsunami sebagai bagian dari sistem peringatan dini tsunami di Indonesia.
\end{abstract}

Kata kunci: GNSS, Sinyal, Pantulan, Permukaan laut, Tsunami

Diterima 30-08-2019 | Disetuiui 30-09-2019| Dipublikasi 31-10-2019 


\section{PENDAHULUAN}

Pemantauan permukaan laut adalah metode penting yang diperlukan untuk memahami aspek-aspek seperti hidrodinamika lokal, aktivitas gelombang pasut dll. Pemantauan permukaan laut juga bisa diterapkan untuk pemantauan cuaca. Konsekuensi dari cuaca ekstrem, seperti topandapat menyebabkan kerusakan besar pada daerah-daerah terutama wilayah pesisir. Lebih besar lagi kerusakan wilayah pesisir yang disebabkan oleh tsunami. Oleh karena itu BMKG telah membangun dan mengoperasikan sistem peringatan dini tsunami setelah gempa dan tsunami Aceh 26 Desember 2004[1].

Di Indonesia, sistem peringatan dini tsunami hanya terbatas pada penerapan model tektonik untuk mendeteksi tsunami. Hingga saat ini, tidak ada detektor tsunami di Indonesia yang menggunakan teknologi GNSS. Teknologi GNSS dapat diterapkan sebagai bagian atau pendukung sistem peringatan dini tsunami, dengan ketentuan bahwa tsunami disebabkan oleh gempa bumi lebih besar dari 7 SR, terjadi 70 kilometer di bawah permukaan laut, dan disebabkan oleh patahan normal [2]. Ini bisa menjadi alternatif untuk buoy GPS yang mahal dalam instalasi dan pemeliharaannya, terutama untuk negaranegara besar seperti Indonesia yang lautannya sangat luas dan mendominasi wilayah Indonesia.

Penelitian ini memperkenalkan dua metode untuk memantau perubahan permukaan laut, yaitu analisis data fase-tunda dan analisis data Signal-to-Noise Ratio (SNR)[3]. Pengamatan satelit GNSS bisa menjadi alternatif untuk melengkapi data yang diperoleh dari satelit altimetri dan dari pengukur pasang surut yang dipasang di daerah pesisir [4]. Permukaan laut absolut juga dapat diukur sehubungan dengan Kerangka Referensi Terestrial Internasional (ITRF) [5].

Makalah ini memberikan pandangan singkat tentang penerapan efek multipath pada deteksi pasang surut dan tsunami dari pengukuran ketinggian permukaan air laut. Simulasi dilakukan menggunakan satu stasiun IGS, JOG2, dan satu Stasiun Referensi Operasi Berkelanjutan (CORS), CLSA, yang masingmasing berlokasi di Jawa dan Sumatra untuk menyelidiki ketersediaan bacaan permukaan laut di Indonesia. Tujuan dari simulasi ini adalah untuk menyelidiki apakah teknologi GNSS cocok untuk deteksi gelombang dan tsunami di Indonesia.

\section{METODE PENELITIAN}

Ketinggian permukaan laut absolut berdasarkan ITRF dapat diperoleh dengan menggunakan dua penerima, penerima RHCP menghadap ke atas (puncak) dan LHCP menghadap permukaan laut (nadir) [6]. Penerima RHCP menerima sinyal yang datang langsung dari satelit GNSS, yang kemudian digunakan untuk memperkirakan posisi absolut antena [7]. Di sisi lain, penerima LHCP menerima sinyal yang dipantulkan oleh permukaan laut [8].

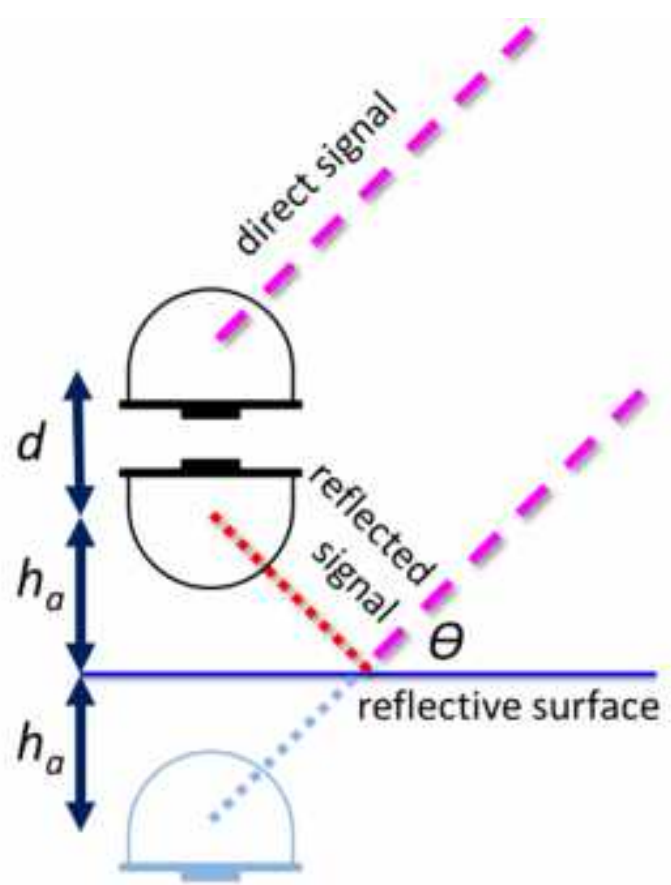

Gambar 1. Susunan antena penerima sinyal langsung sebagai stasiun referensi (paling atas), sinyal pantulan (di bawahnya) dari satelit GNSS dan antena rover bayangan (di bawah permukaan laut). 
Pertama, garis dasar antara antena RHCP dan antena LHCP harus ditentukan untuk mendapatkan perubahan permukaan laut. Susunan antena penerima sinyal langsung dan sinyal pantulan dijelaskan pada Gambar 1.

Gambar 1 menjelaskan bahwa saat antena nadir menerima sinyal pantulan dari permukaan laut, maka dapat dibayangkan menerima sinyal langsung di bawah permukaan laut dengan sudut elevasi sehingga pengamatan sinyal pantulan dianggap sebagai data peneriman rover dan sinyal langsung dianggap sebagai data stasiun referensi. Oleh karena itu penyelesaian posisi antena rover dapat dilakukan dengan metode differensial biasa dalam penentuan posisi relatif. Huruf d pada Gambar 1 tersebut adalah jarak sebenarnya antara antena penerima sinyal langsung dan antena penerima sinyal pantulan, ha adalah ketinggian permukaan laut yang sama dengan ketinggian permukaan air laut dari receiver rover bayangan di bawah permukaan laut.

Jika ketinggian permukaan air laut berubah maka ha akan berubah. Maka ketinggian permukaan laut secara langsung berhubungan dengan jarak garis dasar antara antena referensi dan rover yang secara geometri memiliki hubungan

$\Delta v=2 h_{a}+d$

dimana:

- $\mathrm{v}$ adalah garis dasar antara antena RHCP dan antena LHCP

- $h_{a}$ adalah jarak antara antena LHCP dan permukaan laut

- d adalah jarak antara pusat fase antena RHCP dan antena LHCP

Dengan antena RHCP dan LHCP memungkinkan pengguna untuk mendapatkan perubahan ketinggian permukaan tanah dan ketinggian permukaan laut dalam referensi ITRF. Penentuan posisi antena rover bayangan
menggunakan data fase
Salah satu cara untuk memperkirakan posisi rover bayangan adalah dengan menggunakan metode diferensial. Persamaan pengamatan GNSS untuk dua penerima yang berbeda, A (referensi) dan B (rover), dinyatakan sebagai berikut:

$$
\begin{aligned}
& L_{A}^{j}=\rho_{A}^{j}+c\left(\tau_{A}-\tau^{j}\right)+Z_{A}^{j}-l_{A}^{j}+B_{A}^{j}+ \\
& L_{B}^{j}=\rho_{B}^{j}+c\left(\tau_{B}-\tau^{j}\right)+Z_{B}^{j}-l_{B}^{j}+B_{B}^{j}+
\end{aligned}
$$

Di mana:

$L_{n}^{j} \quad$ : data jarak fase yang teramati $\left(\lambda \Phi_{n}^{j}\right)$

$B_{n}^{j} \quad$ : ambigutas faser $\left(\lambda N_{n}^{j}\right)$ in meters

$\rho_{n}^{j} \quad$ : jarak geometri satelit ke receiver

c : Kecepatan cahaya

$\tau_{n}$ : bias jam receiver

$\tau^{j} \quad$ : bias jam satelit

$Z_{n}^{j}:$ bias troposfer

$l_{n}^{j} \quad$ : bias ionosfer

$E \quad$ : multipath dan noise

Perbedaan antara dua pengamatan sinyal langung (A) dan terpantul (B) dituliskan dalam persamaan:

$\Delta L_{A}^{j}=\Delta \rho_{A}^{j}+c \Delta \tau_{A}+\Delta B_{A}^{j}$

\section{Yang disebut dengan perbedaan tunggal}

Jarak antara dua penerima tersebut atau garis dasar ditulis sebagai

$$
\begin{aligned}
& \Delta \rho_{A}^{i}=\Delta e_{1} \quad\left(a^{i}\right) c_{1} \quad\left(\theta^{i}\right)+ \\
& \Delta n \quad\left(a^{i}\right) c_{1} \quad\left(\theta^{j}\right)+\Delta v \quad\left(\theta^{j}\right)
\end{aligned}
$$

dimana:

$\Delta e, \Delta n, \Delta v \quad:$ komponen timur, utara dan vertikal dari garis dasar

$$
\text { a } \quad \text { : azimuth satelit }
$$$$
\theta \quad \text { : sudut elevasi }
$$

Bias jam receiver dapat dieliminir dengan perbedaan dari persamaan perbedaan tunggal pada dua epok yang berbeda dalam bentuk

$$
V \Delta L_{A}^{j k}=V \Delta \rho_{A}^{j}+V \Delta B_{A}^{j}
$$

\section{Yang disebut perbedaan ganda}


Ambiguitas fase dapat diselesaikan dengan menggunakan metode resolusi ambiguitas integer seperti Least-squares Ambiguity Adjust Decorelation Adjustment (LAMBDA).

Dengan diperolehnya garis dasar atau jarak antara receiver penerima sinyal langsung (A) dan penerima sinyal pantul atau receiver rover bayangan (B') maka ketinggian permukaan laut dapat dihitung dari posisi antena penerima sinyal pantul di B adalah

$$
h_{a}=\frac{\Delta v-d}{2}
$$

Sebelum metode pantulan sinyal GNSS untuk penentuan ketinggian permukaan air laut diterapkan yang bisa dimanfaatkan untuk monitoring gelombang laut dan tsunami, perlu dikaji kelayakannya dalam hal ketersediaan data yang mungkin dipantulkan oleh permukaan laut.

\section{HASIL DAN PEMBAHASAN}

Simulasi dilakukan menggunakan satu stasiun IGS, JOG2, dan satu Stasiun Referensi Operasi Berkelanjutan (CORS), CLSA, yang masing-masing berlokasi di Jawa dan Sumatra untuk menyelidiki ketersediaan dataketinggian permukaan laut di dari dua stasiun tersebut.

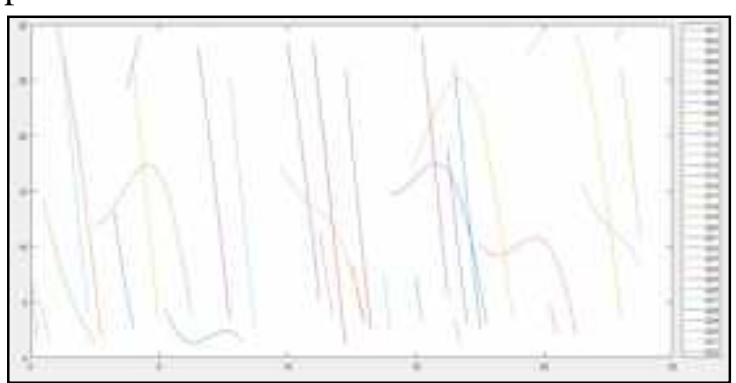

Gambar 2. Sudut elevasi (sumbu y sebelah kiri) satelit GPS dengan nomor seperti ditunjukkan pada sumbu y sebelah kanan, yang terlihat dari alat penerima di Yogyakarta selama 24 jam.

Data yang digunakan untuk simulasi ini adalah koordinat dari kedua stasiun dan ephemeris yang presisi dari satelit GPS.Simulasi dilakukan dengan beberapa ketentuan, seperti azimuth dan sudut ketinggian satelit, dan ketinggian stasiun. Untuk JOG2, hanya azimuth mulai dari $120^{\circ}$ hingga $240{ }^{\circ}$ yaitu dengan asumsi arah gelombang laut dari selatan, dan sudut elevasi mulai dari $1^{\circ}$ dan $30^{\circ}$. Untuk CLSA digunakan data sinyal GPS dari arah azimuth $30^{\circ}$ hingga $150^{\circ}$ yang digunakan dan sudut elevasi $1^{\circ}$ sampai $30^{\circ}$. Ini untuk memastikan bahwa sinyal yang diterima adalah sinyal yang dipantulkan oleh permukaan laut. Untuk kedua stasiun, ketinggiannya ditetapkan 20 meter dari permukaan laut. Asumsi perhitungan titik pantul oleh permukaan laut adalah permukaan laut yang datar sepanjang jarak titik pantul di permukaan laut dan penerima GNSS di pantai.

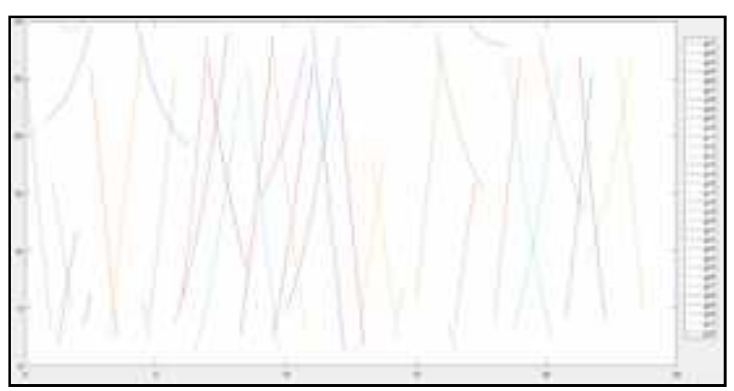

Gambar 3. Sama dengan Gambar 1 kecuali dilihat dengan alat penerima di daerahSumatra dengan kode stasiun CLSA.

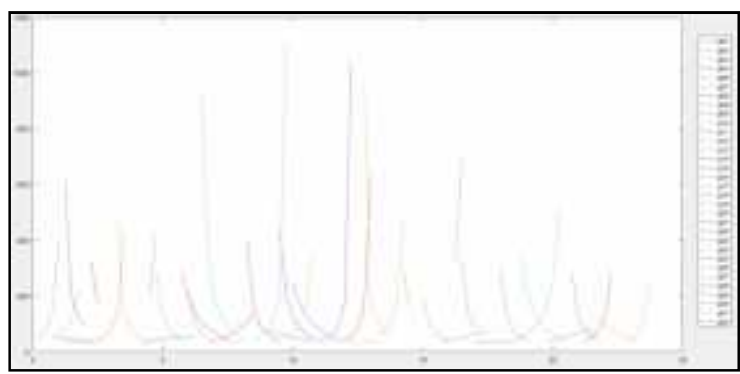

Gambar 4. Jarak titik pantul dari pantai jika sudut elevasi digunakan untuk batas tertinggi sinyal yang dipantulkan oleh permukaan air laut.

Dari Gambar 2diketahui bahwa satelit satelit GPS dapat diamati dengan elevasi kurang dari 30 derajat hampir setiap jam kecuali pukul 9 dan 22 UT. Maka dari itu agar pengamatan sinyal pantulan dinaikkan sudut elevasinya lebih dari 30 derajat untuk dapat digunakan sebagai pengamatan ketinggian permukaan air laut setiap waktu selama 24 jam dalam sehari. 
Dari Gambar 3 ditunjukkan bahwa dengan elevasi kurang dari 30 derajat, satelit GPS dapat diamati selama 24 jam kecuali pada pukul sekitar 14:30-15:00.

Gambar 4 menjelaskan jarak titik pantul yang mungkin dapat memantulkan sinyal GNSS dan diterima di receiver pada ketinggian sekitar 20 meter dari permukaan air laut. Diketahui dari gambar tersebut bahwa jarak terjauh sekitar 1.150 meter dari alat penerima di pantai.

Berdasarkan persamaan kecepatan tsunami yang nilainya sama dengan akar dari percepatan gravitasi dan kedalaman air laut [9], pada 1000 meter tsunami berkecepatan $75,2 \mathrm{~m} / \mathrm{s}$ untuk pantai yang kedalamannya 30 derajat dengan anggapan tsunami berkecepatan konstan akan mencapai pantai selama 13 detik sehingga untuk peringatan dini tsunami waktu tersebut belum cukup bagi masyarakat untuk melakukan persiapan menghindari tsunami. Agar dapat digunakan untuk peringatan dini tsunami ketinggian antenna pemantul sinyal GNSSminimal $60 \mathrm{~m}$ masyarakat mempunyai waktu 39 detik untuk menghindari tsunami.

Disamping untuk pemantauan tsunami metodo pemantauan GNSS dapat digunakan juga untuk pasang surut laut dalam jangka panjang dan resolusi waktu yang tinggi yang tidak mungkin dicapai oleh alat pemantauan pasut tradisional seperti yang dijelaskan oleh Karol Dawidowicz [10].

\section{KESIMPULAN}

Metode pantulan sinyal GNSS untuk penentuan ketinggian permukaan air laut menggunakan teknik yang sudah dikenal sebelumnya yaitu metode penentuan posisi differensial yaitu dengan mencari garis dasar antara antena rover bayangan di bawah permukaan alir laut dan stasiun peneriman sinyal pantul yang sebenarnya di atas permukaan air laut. Kajian sudut elevasi satelit GPS dengan antena penerima sinyal pantulan
GPS pada ketinggian 20 meter menunjukkan bahwa ketersediaan satelit yang teramati secara pantulan sinyal GPS oleh laut hampir 24 jam kecuali pada pukul 11:00 - 11.50.

\section{REFERENSI}

1. Harijono, S.W.B., Harjadi, P.,Fauzi . (2010). InaTEWS(Indonesia Tsunami Early Warning System): Konsep dan Implementasi.Jakarta. Badan Meteorologi Klimatologi dan Geofisika (BMKG).

2. Tilmann, F., Howe, B., Butler, R., Weinstein, S. (2016). Smart Submarine Cable Applications in Earthquake and Tsunami Science and Early Warning. V1.0. http://www.itu.int/en/ITUT/WorkshopsandSeminars/201611/Pages/default.aspx

3. Juhel, K,. Ampuero, J.P., Barsuglia, M., Bernard, P.,Chassande, E., Fiorucci, D., Harms, J., Montagner, J.P, Vall, M., and Whiting, B,F, (2018). Earthquake early warning using future generation gravity strainmeters. JGR Solid Earth.123(12), 10889-10902.

4. Lofgren, J, S. (2014). Local Sea Level Observations Using Reflected GNSS Signals. Thesis for the degree of Doctor of Philosophy. Department of Earth and Space SciencesSpace Geodesy and GeodynamicsChalmers University of TechnologySE-41296 Gothenburg, Sweden.

5. Rudenko, S., Esselborn, S., Schone, T., and Dettmering, D (2019). Impact of terrestrial reference frame realizations on altimetry satellite orbit quality and global and regional sea level trends: a switch from ITRF2008 to ITRF2014. Solid Earth, 10, 293-305.

6. Lofgren, J.,S., and Haas, R (2014). Sea level measurements using multi-frequency GPS and GLONASS observations. EURASIP Journal on Advances in Signal Processing.

7. Chen, C., C., Gao, S., and Maqsoos, M. (2012). Antennas for Global Navigation Satellite System Receivers: in : Willian A Imbriale S, and Gao, L., B: Chapter 14. Space Antenna Handbook.John Wiley \& Sons, Ltd

8. Lofgren, J., S., Haas, R., and Johansson, J., M. (2011). Monitoring Coastal Sea Level Using Reflected GNSS Signals, 47(2), 213--220.

9. Troung, H.,V.,P (2012). Wave-Propagation Velocity, Tsunami Speed, Amplitudes, Dynamic Water-Attenuation Factors. Research Enginering, Westminster Ca 92683, USA.

10. Karol, D. (2014). Sea level changes monitoring using GNSS technology - a review of recent efforts,55(2): $145-162$.

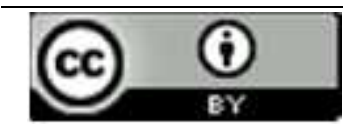

Artikel ini menggunakan lisensi Creative Commons Attribution 4.0 International License 